\title{
BIBLIOTECAS PARA FORMAÇÃO DE TÉCNICOS EM SAÚDE NOS PAÍSES AFRICANOS DE LÍNGUA PORTUGUESA: UM DIAGNÓSTICO
}

\author{
LIBRARIES FOR THE TRAINING OF HEALTH TECHNICIANS IN THE AFRICAN \\ COUNTRIES OF PORTUGUESE LANGUAGE: A DIAGNOSIS
}

\author{
BIBLIOTECAS PARA FORMACIÓN DE TÉCNICOS EN SALUD EN LOS PAÍSES \\ AFRICANOS DE LENGUA PORTUGUESA: UN DIAGNÓSTICO
}

Anderson Leonardo de Azevedo ${ }^{1}$

Resumo O objetivo foi analisar as condições em que se encontram as bibliotecas das instituições de formação de trabalhadores técnicos em saúde dos países africanos de língua oficial portuguesa no âmbito da Rede Internacional de Educação de Técnicos em Saúde. O levantamento dos dados foi realizado mediante pesquisa de campo baseada na aplicação de questionários aos trabalhadores responsáveis pelas bibliotecas ou instituições de ensino. Os resultados mostraram que a maior parte dos trabalhadores das bibliotecas não tinha formação específica para a atividade; o acervo disponível revelou disparidade em relação aos tipos e quantidades de materiais, além de serem apresentados em idiomas que não o português; os recursos físicos eram insuficientes, como ainda o espaço e a localização das bibliotecas; os recursos tecnológicos careciam de melhoria, incluindo-se o acesso à internet. Concluiu-se que as condições das bibliotecas pesquisadas eram insuficientes para oferecer suporte à formação da força de trabalho em nível técnico, como ainda para subsidiar a atividade docente, pois, além da insuficiência e desatualização das obras disponíveis, havia precariedade em instalações, mobiliário e equipamentos.

Palavras-chave Palop; formação técnica em saúde; biblioteca.

\begin{abstract}
The objective was to analyze the conditions in which the libraries of the institutions of training of technical workers in health of the African countries of Portuguese official language within the framework of the International Network of Education of Health Technicians. Data collection was carried out through field research based on the application of questionnaires to workers responsible for libraries or educational institutions. The results showed that most of the workers in the libraries had no specific training for the activity; the available stock revealed a disparity in the types and quantities of materials, besides being presented in languages other than Portuguese; physical resources were insufficient, as were the space and location of libraries; technological resources lacked improvement, including access to the internet. It was concluded that the conditions of the libraries surveyed were insufficient to support the training of the workforce at a technical level, as well as to subsidize the teaching activity, since, in addition to insufficient and outdated works available, there was precariousness in facilities, furniture and equipments. Keywords Palop; technical training in health; library.
\end{abstract}




\section{Introdução}

Nos Países Africanos de Língua Oficial Portuguesa (Palop), a força de trabalho em saúde é reconhecidamente insuficiente e sua composição conjuga uma minoria de profissionais qualificados e outros não qualificados, dos quais não se conhece o exato contingente (Dussault et al., 2010).

A situação de carência, em qualidade e quantidade, enfrentada pelos profissionais de saúde é reflexo das dificuldades relativas às condições de formação de recursos humanos em saúde (RHS), envolvendo precariedade da infraestrutura, falta de pessoal docente, baixa qualidade e irregularidade dos processos formativos, entre outras deficiências. Para melhoria dessas condições, torna-se fundamental que os trabalhadores tenham acesso a condições básicas de trabalho, incluindo-se a formação e a informação (Dussault e Fronteira, 2010).

Nesse contexto, deve-se considerar que as bibliotecas constituem o principal repositório das informações produzidas e organizadas em instituições acadêmicas. Sua existência, organização e gestão adequadas influenciam o acesso à informação e ao conhecimento, favorecendo o desenvolvimento dos seus usuários.

\section{Os Palop e a formação dos técnicos em saúde}

Os Palop são os países da África que têm como língua oficial o português: Angola, Cabo Verde, Guiné-Bissau, Moçambique e São Tomé e Príncipe. Esses países apresentam várias diferenças, contudo guardam como herança semelhante terem sido colônias de Portugal até meados dos anos 1970 e manterem o idioma oficial português. O período colonial deixou marcas políticas, econômicas, sociais e culturais, com numerosos desafios a serem vencidos por esses países (Pereira, 2009).

Os países africanos, colonizados pelos portugueses, viveram segundo a lógica de expansão capitalista, cuja mais evidente característica foi o distanciamento entre o modo de produção do centro e o da periferia, ou seja, entre colonizador e colonizados. A desigualdade social foi aumentada nesse período, o que levou ao crescimento dos esforços de resistência e libertação (Hernández, 2008).

Portugal buscava evitar a separação das colônias africanas, de modo a manter sua dominação (Souza Jr., 2013). Pode-se exemplificar essa situação com a abertura das universidades portuguesas a africanos selecionados entre famílias assimiladas (Fonseca, 2014). ${ }^{2}$

A inserção de africanos nas universidades portuguesas favoreceu a formação de uma elite intelectual e política, que alimentou as lutas por indepen- 
dência nos países africanos (Fonseca, 2014). Em alguns casos, como Angola e Moçambique, o conflito armado foi inevitável. Esses conflitos encontraram continuidade no âmbito interno, mesmo após a independência, marcados por diferentes ideologias políticas (Souza Jr., 2013).

Depois da independência dos países africanos em relação a Portugal, ocorreram rebeliões, disputas de poder, destruição e conflitos, pois esses países, em geral, contavam com um forte partido político, na maioria das vezes um partido único, que não representava, necessariamente, os anseios da população de cada localidade. Tais partidos foram formados, angariaram o apoio de outros partidos menores e da população por ocasião da luta pela independência, porém, posteriormente, se empenharam em tomar o poder, assumindo o governo nacional (Hernández, 2008).

Entretanto, por pressões externas, esses países foram compelidos a adentrar no mercado globalizado, como alternativa para o acesso a bens e serviços e também para alimentar sua balança de pagamentos. Contemporaneamente, em uma tentativa de ajuste às regras de mercado, os Palop enfrentam dificuldades em relação ao crescimento econômico e desenvolvimento, considerando-se, inclusive, aspectos relativos à escolarização da população (Zimba e Mueller, 2008).

Nesse sentido, o apoio internacional, mediante acordos de cooperação, torna-se fundamental para que os Palop melhorem seu desempenho e atinjam a sustentabilidade, visando favorecer a qualidade de vida da população (Zimba e Mueller, 2008). No caso específico da saúde, a formação de profissionais poderá prover melhor distribuição dos RHS e melhor qualificação e capacitação desses profissionais, o que deverá se refletir no acesso e na qualidade da assistência prestada à população.

\section{Formação dos trabalhadores técnicos em saúde}

A formação de trabalhadores técnicos em saúde tem sido um aspecto importante na África, uma vez que a carência de desses profissionais é acentuada. A Organização Mundial da Saúde (OMS) indica que entre os 57 países com déficit de RHS, 36 são africanos e três pertencem ao grupo dos Palop: Moçambique, Angola e Guiné-Bissau (Dussault et al., 2010). O relatório de 2006 da OMS detalha essa situação e estima que o déficit global de RHS atinja 4,3 milhões de trabalhadores em saúde, notadamente médicos, enfermeiras e parteiras (Fronteira e Dussault, 2010). O déficit de RHS na África envolve problemas referentes à quantidade e à distribuição de profissionais de saúde (Martins, 2010).

As condições históricas dos países - como colônias de Portugal - e aquelas vigentes por ocasião da independência de cada um permitem inferir que 
a educação foi relegada a plano inferior. A prática de colonização portuguesa na África obedecia a interesses particulares - envolvendo a geração de receita pelas colônias - e políticos, já que Portugal precisava se fortalecer perante outros países europeus. Para os colonizadores, a educação da população local não era importante, uma vez que eles precisavam manter a força de trabalho sob controle para terem trabalhadores disponíveis para a agricultura e a extração florestal (Lains, 1998).

A precária infraestrutura local foi a herança colonialista para os Palop, incluindo-se a falta de escolas e de assistência à saúde, o que se tornou um desafio para os governos seguintes. A partir de então, esses governos têm enfrentado períodos de instabilidade política, crescimento da dependência externa e pressões para aderir à economia de livre mercado. A globalização, ao mesmo tempo que acena com a possibilidade de crescimento das exportações e receitas, abre caminho para a importação e o crescimento das despesas, o que pode aumentar o desequilíbrio da balança de pagamentos, comprometendo ainda mais a situação econômica desses países.

Por sua vez, os países desenvolvidos e em desenvolvimento, que são doadores e investidores nos Palop, têm interesse nos recursos locais e se empenham na obtenção de contratos favoráveis para suas empresas, tornando-se fornecedores de insumos, máquinas, equipamentos e produtos manufaturados com maior valor agregado. A industrialização local permanece precária, por falta de recursos suficientes - financeiros, mão de obra especializada, tecnologia etc. O desemprego e o subemprego são crescentes e os recursos naturais intensamente prejudicados, entre outras consequências.

\section{A EPSJV e as ações de cooperação internacional}

$\mathrm{Na}$ educação de técnicos em saúde, a Fiocruz atua por meio da Escola Politécnica de Saúde Joaquim Venâncio (EPSJV), destacando-se entre as principais ações empreendidas: assessoria para a estruturação de formação técnica em biodiagnóstico e manutenção de equipamentos em Cabo Verde; assessoria para a reestruturação do Centro Regional de Desenvolvimento Sanitário em Moçambique; formação de profissionais e apoio à formação docente dos agentes comunitários em Angola. A EPSJV também é responsável pela coordenação da Rede de Escolas Técnicas da Comunidade dos Países de Língua Portuguesa (RETS-CPLP) (Roa e Baptista e Silva, 2015; Stauffer, Noronha e Ruela, 2014).

A EPSJV assumiu a Secretaria Executiva da RETS em 2005, reativando a rede que estava suspensa desde 2001. A partir de então, a atuação da RETS se expandiu, permitindo que em 2009 fosse criada a sub-rede RETS/CPLP e a RETS-Unasul (Rede de Escolas Técnicas da Comunidade dos Países de Língua 
Portuguesa, 2012). Entre as atribuições da Secretaria Executiva está a responsabilidade por fornecer "apoio técnico e administrativo para o funcionamento da RETS, inclusive para a elaboração e implementação do seu plano de trabalho" (Rede Internacional de Educação de Técnicos em Saúde, 2006, p. 3).

Em 2013 foi aprovado o Plano de Trabalho para o período de 2014 a 2017, cuja finalidade era

(...) orientar as atividades da Rede Internacional de Educação de Técnicos em Saúde (RETS), a serem desenvolvidas em um período de quatro anos (2014-2017), tendo como pressupostos a integração e a articulação, no âmbito da rede, das instituições de ensino voltadas para formação de técnicos em saúde, de modo a produzir, sistematizar e divulgar conhecimentos que venham a subsidiar a elaboração de políticas, programas, planos e projetos de cooperação internacional e fortalecer os sistemas de saúde dos países membros (Rede Internacional de Educação em Saúde, 2013, p. 1).

A EPSJV, desde a sua idealização, buscou oferecer um ensino técnico que congregasse teoria e prática, de modo a favorecer a instrumentalização profissional e a capacitação intelectual, visando a formação de profissionais de nível médio de maneira ampla e integral. Para tanto, foi estabelecido que a escola poderia contar com a estrutura da Fiocruz, conformando um espaço para a teoria em salas de aula e outro para a prática no campus da instituição. A expertise acumulada pela Fiocruz na educação em saúde constituiu importante suporte para a excelência proposta na formação de técnicos em saúde (Malhão, Cortes e Lima, 2016).

\section{As instituições de ensino nos Palop}

Em relação às instituições de ensino nos Palop, deve-se ressaltar que Portugal não articulou qualquer ação para a educação da população local durante grande parte do período colonial. A partir de 1950, pequena parte da população das colônias portuguesas conseguiu acesso à educação superior fora do seu país de origem, quando o governo, em tentativa de conter as ações pró-independência, facilitou o acesso às suas instituições de nível superior. Um exemplo do desenvolvimento tardio dos países africanos na abertura de escolas de nível superior é o de Angola, que somente em 1962 criou a instituição Estudos Gerais Universitários de Angola, sob a tutela das universidades portuguesas (Fonseca, 2014).

A despeito da pouca disponibilidade de dados das instituições de ensino nos Palop, a Cooperação Internacional da EPSJV/Fiocruz identifica, pelos acordos de cooperação vigentes, 33 instituições de ensino técnico nos países 
do grupo, sendo 15 escolas em Angola, uma em Cabo Verde, uma em GuinéBissau, 15 em Moçambique e uma em São Tomé e Príncipe.

Em Angola, o sistema educacional é composto por seis subsistemas: educação pré-escolar, integrando a creche e o jardim de infância; ensino geral, que integra o ensino primário e o secundário; ensino técnico-profissional, que compreende a formação profissional básica e a formação média-técnica; formação de professores, em dois níveis, sendo o primeiro de formação média normal, que é ministrado nas escolas normais e se destina a formar docentes para os cursos de nível médio, e o segundo o de ensino superior pedagógico, oferecido nos institutos e escolas superiores de ciências da educação; educação de adultos, para indivíduos com mais de 15 anos de idade e que não cumpriram a escolaridade normal, contemplando o ensino primário e o primeiro e o segundo ciclos do ensino secundário; ensino superior, que contempla a graduação, a pós-graduação profissional em nível de especialização e a pósgraduação acadêmica em níveis de mestrado e doutorado (Sunda et al., 2011). Neste estudo, todas as unidades selecionadas em Angola se referem a escolas de formação de técnicos de saúde (EFTSs), destinadas à formação dos técnicos médios e especialistas de nível médio.

Em Cabo Verde, o sistema de ensino abrange: educação pré-escolar, complementando a responsabilidade educativa familiar; educação escolar, que contempla o ensino básico e o ensino secundário, com duração de seis anos e organizado em três ciclos de dois anos, sendo o segundo ciclo composto por uma via geral - que prepara o aluno para a continuação dos estudos - e uma via técnica - que prepara o aluno para a vida ativa -, o terceiro ciclo de especialização, também para as vias geral ou técnica, e o ensino médio profissionalizante, direcionando o aluno para o mercado de trabalho ou a continuação da formação técnica; o ensino superior, que agrega o ensino universitário e o politécnico; educação extraescolar em dois níveis, sendo o primeiro a educação básica de adultos, que inclui a alfabetização e a pós-alfabetização, e o segundo que inclui a aprendizagem e a formação profissional, orientada para a capacitação e o exercício profissional. Em Cabo Verde foi identificada uma universidade que mantém ações de cooperação com a EPSJV, cuja atribuição é a formação politécnica em nível superior (Monteiro, 2008).

Em Guiné-Bissau, o ensino ocorre em duas modalidades: a formal e a não formal. A não formal compreende a alfabetização e o ensino de adultos. O ensino formal ocorre em seis níveis: pré-escolar, destinado a crianças de três a seis anos de idade, sendo opcional e ministrado por uma maioria de auxiliares de educadores não diplomados; básico elementar, que atende crianças de sete a dez anos, sendo obrigatório, contemplando as quatro primeiras classes; básico complementar, que atende crianças de 11 a 12 anos, contemplando a quinta e a sexta classes; secundário, que se divide em geral, com três anos de duração (sétima a nona classes), e complementar, com duração de dois anos 
(décima e $11^{a}$ classes); técnico e profissional, com duração de dois a três anos, oferecendo formação profissionalizante; superior. A Escola Nacional de Saúde é a responsável pela formação dos trabalhadores da saúde em nível técnico, oferecendo cursos de enfermagem, de parteira geral, técnicos de laboratório, técnicos de farmácia, técnicos de saneamento do meio ambiente, técnico social, auxiliar de enfermagem e auxiliares de laboratório (Grupo Guiné-Bissau, 2011).

Não foram localizados dados sistematizados que permitissem verificar o funcionamento do sistema geral de ensino em Moçambique, porém identificaram-se 15 instituições para formação de técnicos em saúde, todas vinculadas ao Ministério da Saúde (Sidat, Fronteira e Dussault, 2010). Os cursos de nível médio são divididos em três categorias: cursos de nível médio especializado, que incluem técnicos especializados em oftalmologia, em cuidados intensivos de enfermagem, em ensino e em administração em enfermagem; cursos de nível médio, que incluem enfermagem geral, saúde materno infantil, medicina geral, medicina preventiva, odontoestomatologia, administração hospitalar, laboratório, farmácia, nutrição, psiquiatria, medicina física e reabilitação, instrumentação, anestesiologia, otorrinolaringologia, estatística sanitária, radiologia, manutenção de equipamento hospitalar, administração em saúde e vigilância epidemiológica; cursos de nível básico, que incluem enfermagem básica, enfermagem de saúde materno infantil, agente de medicina geral, agente de medicina preventiva, agente de odontoestomatologia, agente de administração hospitalar, agente de laboratório e agente de farmácia (Moçambique, 2011).

Em São Tomé e Príncipe não se encontraram dados que possibilitassem verificar a composição do sistema geral de ensino, contudo foi identificada uma unidade que responde pela formação dos técnicos em nível médio (Fronteira, Guerreiro e Dussault, 2010). Essa instituição procura atender às necessidades do mercado, porém com insuficiência no quantitativo de profissionais formados. O país continua enviando estudantes para formação em nível superior no exterior, o que tem se revelado um problema, pois parte significativa deles não retorna (Cunha, Aguiar e Apresentação, 2011).

Assim, a importância da cooperação técnica internacional para os $\mathrm{Pa}$ lop decorre, principalmente, da situação presente nesses países, envolvendo dificuldades relativas aos efeitos das guerras civis e problemas herdados do período colonial, que dificultam a geração de experiência e condições para promover melhoras na saúde da população.

\section{As bibliotecas nos Palop}

Em relatório divulgado em 2009, a World Health Organization indicou que a precariedade das bibliotecas era comum nas instituições formadoras de 
trabalhadores em saúde dos Palop. Em Angola foi estimada a existência de cerca de dez bibliotecas, localizadas nas Escolas Técnicas Provinciais, na Faculdade de Medicina, Escola Nacional de Saúde Pública, no Instituto Nacional de Saúde Pública e no Instituto Médio de Saúde de Moxico - apenas a biblioteca da Faculdade de Medicina estava totalmente estruturada e com acesso à internet; em Cabo Verde foi constatada a existência de computadores nos âmbitos nacional, regional e distrital, porém sem indicação da existência de bibliotecas; em Guiné-Bissau também não foi constatada a existência de bibliotecas; em Moçambique, foi estimada a existência de 17 bibliotecas, distribuídas entre as escolas de ensino superior e médio na área da saúde os computadores existentes estavam alocados nos serviços centrais, sendo o acesso à internet disponível somente em cerca de 50\% das regiões e dos distritos locais; em São Tomé e Príncipe foi relatada a falta de bibliotecas (World Health Organization, 2009).

Nos cinco países verificou-se precariedade da infraestrutura relativa a telecomunicações, eletricidade, equipamentos de informática e acesso à internet (World Health Organization, 2009). Essas condições dificultam o acesso à informação para os profissionais de saúde, especialmente os que atuam nas zonas rurais. Outro fator preocupante revelado pelo relatório da World Health Organization (2009) foi a falta de profissionais com formação específica para atuar nas bibliotecas - o que induz as bibliotecas a terem uma gestão inadequada, acervo insuficiente ou desatualizado, organização e conservação comprometidas, além de desestimular o acesso dos usuários desses espaços. Contudo, é válido ressaltar que esse relatório não contempla todas as bibliotecas pesquisadas no estudo aqui apresentado.

Os governos dos Palop, atentos às necessidades da população, elaboraram programas de melhoria em diversos setores, incluindo-se a educação. Nesse sentido, foi ampliado o número de escolas, cursos regulares e vagas e, consequentemente, de bibliotecas (Cunha, Aguiar e Apresentação, 2011; Fronteira, Guerreiro e Dussault, 2010; Sunda et al., 2011).

\section{Desenho da pesquisa}

Este artigo é baseado na dissertação de mestrado do autor (Azevedo, 2016) e apresenta os resultados da pesquisa sobre as condições em que se encontram as bibliotecas das instituições de formação de trabalhadores técnicos em saúde dos Palop, com os quais a EPSJV/Fiocruz mantém parcerias de cooperação técnica internacional.

Para o levantamento dos dados, foi realizada uma pesquisa de campo baseada na aplicação de questionários aos responsáveis pelas bibliotecas 
ou instituições de ensino, de modo a caracterizar os recursos disponíveis nessas organizações, seu uso e conservação, os horários de funcionamento dessas instituições e das bibliotecas e a formação desses trabalhadores, entre outros aspectos.

A coleta dos dados foi feita pelo pesquisador, sendo intermediada pela Coordenação de Cooperação Internacional (CCI) da EPSJV, mediante e-mail contendo o questionário de pesquisa e o termo de consentimento livre e esclarecido - enviado às 33 bibliotecas das instituições de ensino dos Palop com as quais a EPSJV mantém parceria. Dos questionários enviados, retornaram apenas oito: Angola - enviados 15, respondidos três; Cabo Verde - enviado e respondido um; Guiné-Bissau - enviado e respondido um; Moçambique enviados 15, respondidos dois; São Tomé e Príncipe - enviado e respondido um. Esses questionários constituíram a amostra analisada, cujos respondentes foram identificados por letras do alfabeto, para manutenção do sigilo quanto à sua identidade.

A abordagem foi qualiquantitativa. Realizou-se a análise dos dados mediante codificação das variáveis qualitativas, de modo a promover uma apresentação mais estruturada e favorecer a análise em relação à atuação dos trabalhadores e instalação das bibliotecas. Quanto ao aspecto quantitativo, foram utilizados cálculos de estatística descritiva, buscando dimensionar e comparar os dados levantados.

A pesquisa foi aprovada pelo parecer consubstanciado n. 1.084.035/2015 do Comitê de Ética em Pesquisa (CEP) da EPSJV.

\section{O retrato real das bibliotecas nas instituições de ensino pesquisadas}

A Tabela 1 apresenta os dados referentes ao número de cursos e de alunos das oito instituições pesquisadas, segundo os participantes do estudo. 


\begin{tabular}{|c|c|c|c|}
\hline \multicolumn{4}{|l|}{ Tabela 1} \\
\hline \multicolumn{4}{|c|}{ Número de cursos e de alunos das instituições pesquisadas - 2015} \\
\hline Respondentes & N. de cursos & N. de alunos & Média alunos/curso* \\
\hline A & 4 & 1.623 & 406 \\
\hline B & 8 & não respondeu & - \\
\hline C & 8 & 2.434 & 304 \\
\hline D & não respondeu & não respondeu & - \\
\hline $\mathrm{E}$ & não respondeu & não respondeu & - \\
\hline $\mathrm{F}$ & 8 & 450 & 56 \\
\hline G & 12 & 864 & 72 \\
\hline $\mathrm{H}$ & 2 & 55 & 28 \\
\hline Total & 42 & 5.426 & 129 \\
\hline
\end{tabular}

Fonte: O autor

Nota: *Foram realizados arredondamentos.

A ausência da informação de duas instituições de ensino (D, E) dificultou uma estimativa da distribuição dos cursos e alunos. Entretanto, pôde-se observar que as instituições A e C pareciam concentrar a maior quantidade de cursos e de alunos.

A Tabela 2 apresenta os cursos que cada instituição oferece.

A maior parte dos 46 cursos informados se concentrava em enfermagem geral (13,04\%), análises clínicas/laboratório (13,04\%), farmácia (10,87\%) e radiologia $(8,69 \%)$, totalizando $45,64 \%$ das respostas apresentadas pelos pesquisados. Os demais 25 cursos representavam $54,36 \%$ do total de respostas apresentadas pelos pesquisados.

As instituições pesquisadas informaram horários de funcionamento distintos. As instituições de ensino B e $\mathrm{H}$ apresentaram informações sobre funcionamento nos três turnos (manhã, tarde e noite); as instituições F e G restringiram seu funcionamento até 20h20, enquanto as instituições A e C informaram horário parcial de funcionamento (até $15 \mathrm{~h} 30$ e até 17h30). Os representantes das instituições D e E não responderam à questão.

Entre os oito respondentes, sete se posicionaram afirmativamente ao serem indagados sobre a existência de bibliotecas nas instituições $(A, B, C, E$, F, G, H), enquanto um não se manifestou à questão.

Nas questões específicas sobre as bibliotecas, todos os respondentes dos questionários revelaram atuar como bibliotecários. Os trabalhadores das bibliotecas das instituições pesquisadas tinham idades entre 32 e 55 anos; a maioria (três quartos) era constituída por indivíduos do sexo masculino; predominava a formação acadêmica de nível superior entre esses trabalhadores 
(três quartos); apenas um (F) declarou ter formação específica para a função, ou seja, formação em ciências documentais, arquivos, museus e bibliotecas.

\begin{tabular}{|c|c|c|c|c|c|c|c|c|c|}
\hline \multicolumn{10}{|c|}{ Cursos ofertados pelas instituições pesquisadas - 2015} \\
\hline Cursos técnicos & A & B & C & D & $\mathbf{E}$ & $\mathbf{F}$ & $\mathbf{G}$ & $\mathbf{H}$ & Total \\
\hline Enfermagem geral & 1 & 1 & 1 & - & 1 & 1 & 1 & - & 6 \\
\hline Análises clínicas/laboratório & 1 & 1 & 1 & - & 1 & 1 & 1 & - & 6 \\
\hline Farmácia & 1 & 1 & 1 & - & - & 1 & 1 & - & 5 \\
\hline Radiologia & 1 & 1 & 1 & - & 1 & - & - & - & 4 \\
\hline Estomatologia & - & 1 & 1 & - & - & - & - & - & 2 \\
\hline Oftalmologia & - & 1 & - & - & - & - & 1 & - & 2 \\
\hline Fisioterapia & - & 1 & 1 & - & - & - & - & - & 2 \\
\hline Parteira & - & 1 & - & - & 1 & - & - & - & 2 \\
\hline Nutrição & - & - & 1 & - & - & 1 & 1 & - & 3 \\
\hline Saúde ambiental & - & - & 1 & - & - & - & - & - & 1 \\
\hline Enfermagem em saúde materna e infantil & - & - & - & - & - & 1 & 1 & - & 2 \\
\hline Enfermagem em saúde mental e infantil & - & - & - & - & - & - & - & 1 & 1 \\
\hline Anestesiologia & - & - & - & - & - & - & 1 & 1 & 2 \\
\hline Medicina preventiva e saneamento do meio & - & - & - & - & - & 1 & - & - & 1 \\
\hline Estatística sanitária & - & - & - & - & - & 1 & - & - & 1 \\
\hline Medicina geral & - & - & - & - & - & 1 & 1 & - & 2 \\
\hline Psiquiatria e saúde mental & - & - & - & - & - & - & 1 & - & 1 \\
\hline Medicina física e reabilitação & - & - & - & - & - & - & 1 & - & 1 \\
\hline Instrumentação & - & - & - & - & - & - & 1 & - & 1 \\
\hline Medicina preventiva & - & - & - & - & - & - & 1 & - & 1 \\
\hline Total de cursos por instituição & 4 & 8 & 8 & - & 4 & 8 & 12 & 2 & - \\
\hline Não respondeu & - & - & - & 1 & - & - & - & - & 1 \\
\hline
\end{tabular}

Todos os trabalhadores exerciam a função de bibliotecário, trabalhando nas instituições de ensino pesquisadas em intervalos de tempo diferenciados. O menor era de três anos (H) e o maior de 15 anos (C), porém o exercício da função foi relatado em intervalos de seis meses (B) a 15 anos (C). Em relação ao horário de funcionamento das bibliotecas, pôde-se observar que havia funcionamento parcial, com horários das 7h30/8h às 15h30/16h (A, C, E, H), manhã e noite (B) e horários integrais (6h45 às 20h20/20h30; F, G). 


\section{Recursos humanos nas bibliotecas}

A quantidade de trabalhadores nas bibliotecas variou entre um e quatro trabalhadores. Apenas um pesquisado declarou ter formação específica para a atividade (F), e cerca de metade (B, D, E, F) desses trabalhadores receberam capacitação para atuar na função. Os pesquisados foram unânimes em reconhecer a necessidade de formação/capacitação para o exercício da função, destacando que o tipo de formação/capacitação necessária envolve aspectos específicos de biblioteconomia.

\section{Acervo das bibliotecas}

O acervo disponível nas instituições pesquisadas revelou disparidade significativa em relação aos tipos e quantidades de materiais, conforme apresentado na Tabela 3.

\section{Tabela 3}

\begin{tabular}{l|c|c|c|c|c|c|c|c}
\hline \multicolumn{2}{l}{ Características dos acervos disponíveis nas bibliotecas das instituições pesquisadas - 2015 } \\
\hline $\begin{array}{l}\text { Exemplares } \\
\text { disponíveis }\end{array}$ & A & B & C & D & E & F & G & H \\
\hline Livros & 2.000 & 1.109 & 153 & 14.401 & 1.572 & 6.366 & 2.855 & 400 \\
Revistas/periódicos & 378 & - & - & - & 67 & $\begin{array}{c}153 \text { títulos/ 8.340 } \\
\text { exemplares }\end{array}$ & - & 100 \\
& & & & & & & & \\
Boletins & 29 & - & - & - & - & - & - & - \\
Folhetos & 122 & - & - & - & - & - & - & - \\
DVD & - & 22 & - & - & 5 & 3 & - & 5 \\
CD & - & - & - & - & 16 & 17 & - & - \\
\hline
\end{tabular}

Fonte: $\mathrm{O}$ autor.

A maior parte do acervo existente nas instituições pesquisadas era composta por livros, sendo que revistas e periódicos foram informados apenas nas instituições A, E e F; DVD nas instituições B, E, F e H; CD em E e F; boletins e folhetos apenas na instituição do respondente A.

Os respondentes foram unânimes em admitir que a maior parte do acervo disponível nas bibliotecas das instituições pesquisadas era no idioma português, porém apenas um (B) declarou que a instituição não tinha publicações em outros idiomas, enquanto os demais informaram haver obras em outros idiomas. Nas instituições A, B, C e D, a existência de acervo em outros idiomas foi considerada favorável ao aprendizado dos alunos, destacando-se que na 
instituição C o inglês era o idioma com que se convivia com frequência e no qual eram lecionados cursos para formação em outros idiomas, incluindo-se o mandarim. No entanto, o português foi considerado o idioma preferencial dos usuários das bibliotecas, com exceção do respondente E, que indicou também o espanhol.

A maior parte das bibliotecas das instituições pesquisadas (B, D, E, F, G) foi considerada pelos pesquisados com acervo desatualizado. $\mathrm{O}$ acervo foi considerado insuficiente e inadequado (A, B, C, D, E, F, G, H), devido à falta de obras e de obras atualizadas para alguns cursos (A, C, E, F). Três quartos das bibliotecas das instituições pesquisadas (A, B, D, E, G, H) informaram que era liberado o acesso às comunidades locais, enquanto as demais $(\mathrm{C}, \mathrm{F})$ não permitiam esse acesso.

\section{Recursos físicos e tecnológicos disponíveis nas bibliotecas}

Os recursos físicos disponíveis nas bibliotecas também revelaram disparidade em vários aspectos. Apenas três unidades (B, F, G) entre as oito bibliotecas pesquisadas foram consideradas pelos respondentes como detentoras de espaços adequados. As demais revelaram localização inadequada $(\mathrm{E}, \mathrm{H})$, assim como tamanho do espaço $(\mathrm{A}, \mathrm{C}, \mathrm{H})$ e deficiência nos recursos físicos $(\mathrm{B}, \mathrm{C}$, D, E, G, H), prejudicando a distribuição, a organização e a conservação do acervo, bem como o atendimento aos usuários. Foi citada também a falta de recursos tecnológicos (fotocopiadoras, impressoras e computadores) (C, D, E).

Em relação aos recursos tecnológicos disponíveis nas bibliotecas pesquisadas, cerca de um terço dos pesquisados (B, D, F) declararam que existia software para gestão do acervo. Todos os pesquisados informaram haver disponibilidade de computadores para os funcionários nas bibliotecas, sendo que apenas um terço dos respondentes declararam ter acesso à internet nas bibliotecas (D, G, H). Os demais recursos tecnológicos - impressora, scanner, aparelho de $\mathrm{TV}$, de som, de DVD, projetor e computador para usuários - somente foram citados pelo representante de uma instituição (F), e alguns desses recursos nas bibliotecas representadas pelos demais (B, D, G, H). Todos os pesquisados informaram que as bibliotecas precisavam incrementar os recursos tecnológicos disponíveis, enfatizando melhorias para os usuários das instituições de ensino, a gestão do acervo e o acesso à internet.

Ao serem solicitados a apresentar comentários adicionais, somente os pesquisados $\mathrm{C}, \mathrm{E}, \mathrm{F}$ e $\mathrm{H}$ se manifestaram. O pesquisado $\mathrm{C}$ concentrou suas observações na necessidade de formação em biblioteconomia para os trabalhadores das bibliotecas e para a melhoria do atendimento aos usuários, bem como na necessidade de se ter acesso a bibliotecas virtuais e de contar com acervo online, possivelmente para melhorar a sua gestão. $\mathrm{O}$ pesquisado $\mathrm{E}$ observou que seria importante uma investigação in loco acerca das condições 
oferecidas pela biblioteca, visando à formulação de recomendações específicas para unidades que apresentassem características semelhantes. O pesquisado F ressaltou a importância da formação adequada dos trabalhadores das bibliotecas, a necessidade de troca de experiências interna e externamente, a instalação de salas de leitura e a constituição de um fundo financeiro para aquisição dos materiais necessários e manutenção da integridade e conservação do acervo existente. O pesquisado $\mathrm{H}$ enfatizou a necessidade de melhorar o espaço físico da biblioteca, descrevendo que o tamanho do cômodo não comportava a presença de três pessoas ao mesmo tempo.

\section{Análise da situação apresentada pelas bibliotecas}

Em relação ao número de cursos e alunos de cada instituição foi impossível tecer qualquer comentário, dada a disparidade entre as instituições e a abstenção de respostas. Contudo, foi possível observar que havia diversidade de cursos ofertados pelas instituições de ensino, que possivelmente buscavam suprir as necessidades locais, uma vez que a qualidade da formação e o desequilíbrio geográfico na distribuição de RHS foram evidenciados em todos os países dos Palop (Dussault et al., 2010; Organização Mundial da Saúde, 2008, 2009a, 2009b, 2009c; Neves, Fronteira e Dussault, 2010; Sidat, Fronteira e Dussault, 2010; Silva, Fronteira e Dussault, 2010).

O horário de funcionamento das instituições de ensino foi diversificado, com funcionamento parcial em algumas delas - o que possivelmente se refletia na reduzida oferta de vagas. Porém, deve-se levar em consideração que pode haver falta de professores ou instrutores para suprir a demanda local (Neves, Fronteira e Dussault, 2010; Organização Mundial da Saúde, 2008).

Sobre o horário de funcionamento das bibliotecas, observou-se que apenas a instituição do respondente $\mathrm{H}$ relatou funcionamento em horário inferior ao da instituição de ensino, de forma que pode levar ao prejuízo de alunos, que ficam impedidos de utilizar os recursos disponíveis no local, além de comprometer a finalidade educativa da biblioteca (Morigi e Souto, 2005; Queiroz, 2006).

Acerca dos responsáveis pelas bibliotecas, pôde-se observar que eram adultos jovens, a maior parte do sexo masculino, com formação, de nível superior e tempo de trabalho significativo nas instituições e no exercício da função.

A quantidade de trabalhadores nas bibliotecas foi variada, não parecendo haver relação entre a quantidade de cursos e alunos para o dimensionamento de pessoal. Apenas um desses trabalhadores revelou ter formação em biblioteconomia; a metade afirmou ter recebido alguma formação/capacitação para atuar na função, porém todos admitiram que havia necessidade de formação/ capacitação para os trabalhadores das bibliotecas. O tipo de formação/capacitação citado pelos pesquisados foi relativo à função da própria biblioteca e ao 
exercício da função. A fragilidade da formação acadêmica pareceu ressaltada nesse aspecto, corroborando as informações de diferentes autores acerca da baixa qualidade e da falta de acesso ao ensino nos Palop (Fronteira, Guerreiro e Dussault, 2010; Lorenzoni, 2008; Morigi e Souto, 2005; Organização Mundial da Saúde, 2008, 2009a).

O acervo disponível nas bibliotecas era, majoritariamente, composto por livros no idioma português. Porém, foram registradas obras em outros idiomas, nem sempre apropriadas aos cursos. Isso decorre, especialmente, em razão de essas instituições receberem doações de diversos países de língua estrangeira, por meio de acordos de cooperação (Iglesias Puente, 2010).

Em termos gerais, a qualidade do acervo disponível nas bibliotecas pesquisadas era baixa, com edições muito antigas, exemplares insuficientes e de obras relacionadas a diversos cursos - o que indica que, possivelmente, não havia verba ou, pelo menos, se houvesse, era insuficiente para a atualização do acervo. Tal fato pode, inclusive, indicar que a biblioteca é subestimada em sua importância ou relegada a planos inferiores no planejamento e na distribuição de recursos (Ribeiro, 2008).

Outros aspectos que corroboraram as deficiências existentes nas bibliotecas referiram-se a sua localização inadequada, espaço restrito e mobiliário insuficiente e inadequado, afetando a organização e a conservação do acervo, assim como as condições de trabalho e o atendimento aos usuários (Ribeiro, 2008).

Os recursos tecnológicos eram escassos, observando-se que algumas instituições realizavam a gestão do acervo manualmente; apenas três delas informaram ter acesso à internet. Tal acesso parecia ser precário e não disponível para todos os trabalhadores e usuários. No contexto educacional, isso resulta em limitação na atualização das informações e no desenvolvimento acadêmico (Deus, 2011; Morigi e Souto, 2005). A necessidade de melhoria dos recursos tecnológicos foi confirmada por todos os pesquisados, demonstrando o reconhecimento das limitações existentes no exercício da função e dos serviços prestados.

A pesquisa revelou também que as bibliotecas das instituições de ensino técnico dos Palop, no âmbito dos respondentes, se encontravam em situação de vulnerabilidade e com sua função comprometida. Esses aspectos se evidenciaram pela qualidade do acervo, por menções a dificuldades de conservação, disposição, organização e controle desses itens.

Ainda no que diz respeito ao acervo, a origem da maior parte desses materiais parecia ser a doação, o que atendia mais aos interesses do doador do que à necessidade dos receptores. Parecia haver falta de conhecimento ou interesse desses doadores quanto às reais necessidades e cursos realizados nas escolas que recebiam as doações. A falta de conhecimento de parte significativa dos alunos em idiomas estrangeiros (inglês, francês e espanhol, entre outros) parecia não ser relevante para os doadores de obras impróprias para 
uso, ou talvez os receptores fossem considerados depositários de obras que não mais interessassem aos doadores.

Em relação à composição e à atualização do acervo, cumpre ressaltar que, além de atender às especificidades técnicas dos cursos oferecidos pela escola, elas devem estar articuladas às concepções pedagógicas que orientam sua atuação. A função da biblioteca nos Palop, consoante o seu papel de suporte pedagógico, segue, nessa perspectiva, cada vez mais fragilizada - devido à precária contribuição e ao conflito com a proposta educacional contemporânea.

A ausência de conhecimentos específicos para atuação nas bibliotecas foi reconhecida pelos pesquisados, indicando que a oferta de capacitação se mostrou insuficiente para prover os conhecimentos necessários à função. Essa falta de conhecimento foi acompanhada pela falta de recursos humanos, físicos e tecnológicos nas unidades pesquisadas, pois houve forte evidência de seu subdimensionamento.

A dificuldade de acesso à internet pareceu incomodar todos os pesquisados. Essa tecnologia é especialmente atraente, pois possibilita o acesso a diferentes meios de informação - o que pode configurar um problema adicional, uma vez que as estruturas de comunicação e de controle parecem frágeis. $\mathrm{Na}$ vigência dessa fragilidade, como seria possível instalar e liberar o acesso à rede mundial de computadores, delimitar o seu uso em pesquisa acadêmica e excluir a rede social e outros tipos de interesse e acessos indevidos? O nível de conscientização e de formação dos gestores das bibliotecas precisaria ser aprimorado, assim como as ferramentas de controle e fiscalização.

Em suma, a fragilidade dessas instituições foi bastante evidenciada, requerendo ações específicas para sua mitigação, conquanto se leve em consideração o perfil de cada país e de cada instituição de ensino, as limitações de recursos financeiros, materiais e da força de trabalho.

\section{Reflexões finais}

A abordagem dos Palop e das condições das bibliotecas das instituições de formação de trabalhadores técnicos em saúde permitiu que se chegasse a algumas conclusões, como a de que os trabalhadores dessas bibliotecas tinham formação acadêmica distinta da exigida pela função, na maior parte em nível superior, porém reconhecendo que careciam de formação/ capacitação adequada para suas atividades laborais. Também se verificou que os recursos físicos e tecnológicos disponíveis nas bibliotecas eram precários e insuficientes, notadamente por falta de espaço e equipamentos, o que podia se relacionar à insuficiência de planejamento e de recursos financeiros. E que o acervo das instituições pesquisadas era de baixa qualidade, insuficiente em quantidade e adequação aos cursos, o que podia estar associado à 
insuficiência de planejamento e de recursos financeiros para aquisição e conservação desses itens e, talvez, a uma certa acomodação à oferta de obras provenientes dos acordos de cooperação, muitas vezes impróprias para o fim a que se destinam.

Consoante o objetivo proposto, convém destacar que as condições apresentadas pelas bibliotecas pesquisadas foram insuficientes para oferecer suporte à formação da força de trabalho em nível técnico e para subsidiar a atividade docente, pois, além da insuficiência e desatualização do acervo, havia precariedade em instalações, mobiliário e equipamentos.

Uma limitação importante do estudo foi a pequena amostra analisada. Porém, diante do histórico dos países do grupo dos Palop, é provável que essa situação encontre semelhança nas demais instituições que não participaram da pesquisa. Recomenda-se cautela no uso e na extrapolação dos resultados obtidos, uma vez que os governos desses países parecem estar se empenhando em melhorar a qualidade da formação dos RHS e sua distribuição geográfica.

Outra importante limitação foi a falta de informações atualizadas, considerando-se que esses países não oferecem tais informações em suas páginas oficiais na internet e que as pesquisas divulgadas são escassas, devido, possivelmente, à falta de recursos e pesquisadores e à localização geográfica dos países. Tal fato evidencia a necessidade de novos estudos sobre o tema, inclusive para subsidiar as ações de cooperação.

Nesse contexto, a biblioteca deixa de ser entendida como recurso para a facilitação do processo de ensino-aprendizagem quando não é utilizada como recurso pedagógico, quando seu uso não é incentivado, ou mesmo quando não é gerida adequadamente e seu acervo e instalações são preteridos ou ignorados. Entretanto, é importante enfatizar que a sua precariedade é sentida e foi demonstrada no estudo aqui apresentado, mediante observações dos pesquisados acerca, principalmente, da baixa qualidade atribuída ao acervo disponível. A sua influência na formação da força de trabalho de nível técnico não pode, portanto, ser dimensionada.

Resumen El objetivo fue analizar las condiciones en que se encuentran las bibliotecas de las instituciones de formación de trabajadores técnicos en salud de los países africanos de lengua oficial portuguesa en el marco de la Red Internacional de Educación de Técnicos en Salud. El levantamiento de los datos fue realizado mediante investigación de campo basada en la aplicación de cuestionarios a los trabajadores responsables de las bibliotecas o instituciones de enseñanza. Los resultados mostraron que la mayoría de los trabajadores de las bibliotecas no tenían formación específica para la actividad; el acervo disponible mostró disparidad en relación a los tipos y cantidades de materiales, además de ser presentados en idiomas distintos del portugués; los recursos físicos eran insuficientes, como el espacio y la localización de las bibliotecas; los recursos tecnológicos carecían de mejora, incluyendo el acceso a Internet. Se concluyó que las condiciones de las bibliotecas investigadas eran insuficientes para brindar apoyo a la formación de la fuerza de trabajo a nivel técnico, así 
como para subsidiar la actividad docente, pues, además de la insuficiencia y desactualización de las obras disponibles, había precariedad en instalaciones, mobiliario y equipos.

Palabras clave Palop; formación técnica en materia de salud; biblioteca.

\section{Notas}

${ }^{1}$ Fundação Oswaldo Cruz, Escola Politécnica de Saúde Joaquim Venâncio.

$<$ andersonazevedo@fiocruz.br>

Correspondência: Fundação Oswaldo Cruz, Escola Politécnica de Saúde Joaquim Venâncio, Avenida Brasil, 4.365, CEP 21040-900, Manguinhos, Rio de Janeiro, RJ, Brasil.

${ }^{2}$ Eram os nativos que atendiam às "seguintes condições: $1^{\circ}-$ saber ler e escrever a língua portuguesa; $2^{\circ}$ - possuir os meios necessários à sua subsistência e à das suas famílias; $3^{\circ}$ - ter bom comportamento atestado pela autoridade administrativa da área em que reside; $4^{\circ}$ - diferenciar-se pelos seus usos e costumes do usual da sua raça" (Hernández, 2008, p. 105).

\section{Referências}

AZEVEDO, Anderson L. Análise das condições de funcionamento das bibliotecas nas instituições de formação dos trabalhadores técnicos em saúde nos Países Africanos de Lingua Oficial Portuguesa (Palop). 2016. 124f. Dissertação (Mestrado em Educação Profissional em Saúde) - Fundação Oswaldo Cruz, Escola Politécnica de Saúde Joaquim Venâncio, Rio de Janeiro, 2016.

CUNHA, Cesaltino; AGUIAR, Eurídice H.; APRESENTAÇÃO, Pascoal. Políticas públicas de educação profissional em saúde na República Democrática de São Tomé e Príncipe. In: SEMINÁRIO ‘ESPECIALIZAÇÃO EM EDUCAÇÃO PROFISSIONAL EM SAÚDE PARA OS PAÍSES AFRICANOS DE LÍNGUA OFICIAL PORTUGUESA'. Rio de Janeiro, 2011. Rio de Janeiro: Escola Politécnica de Saúde Joaquim Venâncio, Fundação Oswaldo Cruz, 2011.
DEUS, Cássia C. R. D. Evolução das bibliotecas universitárias e suas relações com as políticas educacionais no Brasil. In: CONGRESSO BRASILEIRO DE BIBLIOTECONOMIA, DOCUMENTAÇÃO E CIÊNCIA DA INFORMAÇÃO, 24, 2011, Maceió. Anais... São Paulo: Febab, 2011 .

DUSSAULT, Gilles et al. (orgs.). Análise dos recursos humanos da saúde (RHS) nos países africanos de lingua oficial portuguesa (Palop). Geneva: WHO, 2010. 126p.

DUSSAULT, Gilles; FRONTEIRA, Inês. Síntese sobre a situação dos RHS nos Palop. In: DUSSAULT, Gilles et al. (eds.). Análise dos recursos humanos da saúde (RHS) nos países africanos de lingua oficial portuguesa (Palop). Geneva: WHO, 2010. p. 108-111. 
FONSECA, Dagoberto J. Cooperando com a África: Portugal e Brasil - o papel das universidades e de outras redes socioculturais, o caso de Angola. O Público e o Privado, Fortaleza, n. 23, p. 55-72, 2014.

FRONTEIRA, Inês; DUSSAULT, Gilles. Recursos humanos da saúde nos países africanos de língua oficial portuguesa: problemas idênticos, soluções transversais?. RECIIS: Revista Eletrônica de Comunicação, Informação \& Inovação, Rio de Janeiro, v. 4, n. 1, p. 78-85, mar. 2010. Disponível em: <https://www.reciis.icict. fiocruz.br/index.php/reciis/article/view/701>. Acesso em: 1 out. 2013.

FRONTEIRA, Inês; GUERREIRO, Catia; DUSSAULT, Gilles. Ponto da situação para Angola. In: DUSSAULT, Gilles et al. (orgs.). Análise dos recursos humanos da saúde (RHS) nos paises africanos de lingua oficial portuguesa (Palop). Geneva: WHO, 2010. p. 16-33.

GRUPO GUINÉ-BISSAU. Seminário (Especialização em Educação Profissional em Saúde para es Países Africanos de Língua Oficial Portuguesa). Rio de Janeiro: Escola Politécnica de Saúde Joaquim Venâncio, Fundação Oswaldo Cruz, 2011.

HERNÁNDEZ, Leila M. G. L. A África na sala de aula: visita à história contemporânea. 4. ed. São Paulo: Selo Negro, 2008. 678p.

IGLESIAS PUENTE, Carlos A. A cooperação técnica horizontal brasileira como instrumento de politica externa: a evolução da cooperação técnica com países em desenvolvimento - CTPD - no período 1995/2005. Brasília: Funag, 2010. 340p.

LAINS, Pedro. Causas do colonialismo português em África, 1822-1975. Análise Social, Lisboa, v. 33, p. 463-496, 1998.

LORENZONI, Ionice. Países de língua portuguesa debatem analfabetismo. 27 fev. 2008. Disponível em: < http://portal.mec.gov.br/busca-geral/204noticias/10899842/9964-sp-1350877086>. Acesso em: 13 out. 2017.
MALHÃO, André P.; CORTES, Bianca A.; LIMA, Júlio C. F. Escola Politécnica de Saúde: uma utopia em construção. In: ESCOLA POLITÉCNICA DE SAÚDE JOAQUIM VENÂNCIO. Caminhos da politecnia: 30 anos da Escola Politécnica de Saúde Joaquim Venâncio. Rio de Janeiro: Escola Politécnica de Saúde Joaquim Venâncio, 2016. p. 13-38.

MARTINS, Mariana R. A cooperação em saúde entre o Brasil e os países africanos de língua oficial portuguesa (2003-2010). 2010. 91f. Trabalho de Conclusão de Curso (Bacharelado em Relações Internacionais) - Universidade Federal do Rio Grande do Sul, Porto Alegre, 2010.

MOÇAMBIQUE. Ministério da Saúde. Direcção Nacional de Recursos Humanos. Plano Nacional de Formação 2011-2015 por instituição de formação. Maputo: Ministério da Saúde, 2011.

MONTEIRO, Mário L. G. S. Integração de sistema educativo cabo-verdiano utilizando web services: o caso das matrículas. 2008. 91f. Monografia (Curso de Engenharia de Sistemas e Informática) - Universidade Jean Piaget de Cabo Verde, Cidade da Praia, 2008.

MORIGI, Valdir J.; SOUTO, Luzane R. Entre o passado e o presente: as visões de biblioteca no mundo contemporâneo. Revista $A C B$ : Biblioteconomia em Santa Catarina, Florianópolis, v. 10, n. 2, p. 189-206, jan.-dez. 2005.

NEVES, Clotilde; FRONTEIRA, Inês; DUSSAULT, Gilles. Ponto da situação para a Guiné-Bissau. In: DUSSAULT, Gilles et al. (eds.). Análise dos recursos humanos da saúde (RHS) nos países africanos de lingua oficial portuguesa (Palop). Geneva: WHO, 2010. p. 53-69.

ORGANIZAÇÃO MUNDIAL DA SAÚDE (OMS). Escritório Regional Africano, República do Congo. Estratégia de cooperação da OMS com os países 2009-2013: Guiné-Bissau. 2008. Disponível em: <http://apps.who.int/iris/ bitstream/10665/137175/1/ccs_gnb.pdf > . Acesso em: 13 out. 2017. 36f. 
ORGANIZAÇÃO MUNDIAL DA SAÚDE (OMS). Escritório Regional Africano, República do Congo. Estratégia de Cooperação da OMS com os países 2009-2013: Angola. 2009a. Disponível em: <http://apps.who.int/iris/ bitstream/10665/135966/1/ccs_ago_po.pdf >. Acesso em: 13 out. 2017. 35f.

ORGANIZAÇÃO MUNDIAL DA SAÚDE (OMS). Escritório Regional Africano, República do Congo. Estratégia de Cooperação da OMS com os países 2008-2013: Cabo Verde. 2009b. Disponível em: <http://apps.who.int/iris/ bitstream/10665/135974/1/ccs_capev.pdf > . Acesso em: 13 out. 2017. 34f.

ORGANIZAÇÃO MUNDIAL DA SAÚDE (OMS). Escritório Regional Africano, República do Congo. Estratégia de Cooperação da OMS com os países 2008-2013: São Tomé e Príncipe. 2009c. Disponível em: <http://apps.who.int/ iris/bitstream/10665/137363/1/ccs_stp.pdf > . Acesso em: 13 out. 2017. 46f.

PEREIRA, Fábio A. L. Portugal e os países africanos de língua oficial portuguesa (Palop). Relatório de estudo. 2009. Disponível em: $<$ https://issuu.com/fabper/docs/relat_rio_ de_estudo_portugal_e_os_palop $>$. Acesso em: 13 out. 2017.

QUEIROZ, Antônia M. C. A biblioteca, uma organização sociocultural e instrumento a serviço da educação e cidadania. 2006. 53f. Monografia (Especialização em Metodologia da Educação Superior) - Faculdade Batista Brasileira, Salvador, 2006.

REDE DE ESCOLAS TÉCNICAS DA COMUNIDADE DOS PAÍSES DE LÍNGUA PORTUGUESA (RETS). RETS: a história como base para a ação atual. RETS, Rio de Janeiro, ano 3, n. 13, p. 2-4, jan.-fev.-mar. 2012. Disponível em: $<$ http:// www.rets.epsjv.fiocruz.br/sites/default/files/ revistas/rets13_pt.pdf $>$. Acesso em: 13 out. 2017.

REDE INTERNACIONAL DE EDUCAÇÃO DE TÉCNICOS EM SAÚDE. Regulamento da Rede Internacional de Educação de Técnicos em Saúde. 2006. Disponível em: <http://www.rets. epsjv.fiocruz.br/sites/default/files/arquivos/ biblioteca/regulamento_pt.pdf $>$. Acesso em: 16 nov. 2015.

REDE INTERNACIONAL DE EDUCAÇÃO DE TÉCNICOS EM SAÚDE. Plano de trabalho 2014-2017. 2013. Disponível em: <http:// www.rets.epsjv.fiocruz.br/sites/default/ files/arquivos/biblioteca/2013_rets_planode-trabalho_2014-2017_pt.pdf>. Acesso em: 16 nov. 2015.

RIBEIRO, Alexsander B. Bibliotecas públicas do Brasil: passado, presente e futuro. 2008. 21 lf. Monografia (Graduação em Biblioteconomia) - Universidade Federal do Rio Grande do Sul, Porto Alegre, 2008.

ROA, Alejandra C.; BAPTISTA E SILVA, Felipe R. A Fiocruz como ator da política externa brasileira no contexto da Comunidade dos Países de Língua Portuguesa: uma história revelada. História, Ciências, Saúde: Manguinhos, Rio de Janeiro, v. 22, n. 1, p. 153-169, jan.-mar. 2015.

SIDAT, Moshin; FRONTEIRA, Inês; DUSSAULT, Gilles. Ponto da situação para Moçambique. In: DUSSAULT, Gilles et al. (orgs.). Análise dos recursos humanos da saúde (RHS) nos países africanos de língua oficial portuguesa (Palop). Geneva: WHO, 2010. p. 70-93.

SILVA, Rosa; FRONTEIRA, Inês; DUSSAULT, Gilles. Ponto da situação para Cabo Verde. In: DUSSAULT, Gilles et al. (eds.). Análise dos recursos humanos da saúde (RHS) nos países africanos de lingua oficial portuguesa (Palop). Geneva: WHO, 2010. p. 34-52.

SOUZA JR., Fernando. O nacionalismo africano no caminho para a democracia: a transição do poder colonial para o partido único nos Palop. Centro de Estudo sobre África e do Desenvolvimento. Working Paper, Lisboa, $\mathrm{n}$. 119, 2013. Disponível em: <https://pascal. iseg.utl.pt/ cesa/files/Doc_trabalho/WP119. pdf $>$. Acesso em: 13 ou. 2017.

STAUFFER, Anakeila B.; NORONHA, Ana B. M.; RUELA, Helifrancis C. G. Escola Politécnica 
de Saúde Joaquim Venâncio: 10 anos como Centro Colaborador da OMS para a Educação de Técnicos em Saúde. Rio de Janeiro: Escola Politécnica de Saúde Joaquim Venâncio, 2014.

SUNDA, Abel et al. Curso (Especialização em Educação Profissional em Saúde para os Países Africanos de Língua Oficial Portuguesa). Trabalho de seminário elaborado pelos alunos de Angola. Rio de Janeiro: Escola Politécnica de Saúde Joaquim Venâncio, Fundação Oswaldo Cruz, 2011.

WORLD HEALTH ORGANIZATION (WHO). Relatório do acesso à informação nos Palop. 2009. Disponível em: <http://cspace.eportuguese.org/tiki-download_file.php?fileId=917>. Acesso em: 14 mar. 2015.

ZIMBA, Horácio F.; MUELLER, Suzana P. M. A presença dos países africanos de língua oficial portuguesa - Palop - em bases de dados ISI e
SOCUPS [sic]: análise comparativa 1998-2007. In: CONFERÊNCIA IBERO-AMERICANA DE PUBLICAÇÕES ELETRÔNICAS NO CONTEXTO DA COMUNICAÇÃO CIENTÍFICA - CIPECC, 2., Rio de Janeiro, 2008. Rio de Janeiro: CIPECC, 2008. Disponível em: <https://www. researchgate.net/profile/Horacio_Francisco_Zimba/ publication/236852865_A_presenca_dos_paises_ africanos_de_lingua_oficial_portuguesa_-PALOP_-_em_bases_de_dados_ISI_e_ SOCUPS_analise_comparativa_1998-2007/ links/0c96051971f41738a0000000/A-presencados-paises-africanos-de-lingua-oficialportuguesa-PALOP-em-bases-de-dados-ISIe-SOCUPS-analise-comparativa-1998-2007. pdf>. Acesso em: 13 out. 2017.

Recebido em 11/07/2016. Aprovado em 15/08/2017. 
